\title{
PENGARUH IKLIM ORGANISASI, KOMUNIKASI INTERPERSONAL DAN KEPUASAN KERJA TERHADAP KINERJA
}

\author{
Ahmad Faisal dan Istiyah \\ dosen dan mahasiswa S2 Unsurya \\ ebankfaisal@gmail.com
}

\begin{abstract}
This study aims to find out about the influence between Organizational Climate, Interpersonal Communication and Job Satisfaction on the performance of NCO / Tamtama in Kodiklatau.

Data derived from questionnaires distributed were analyzed data, among others: description of data, testing of research requirements, including: normality test, homogeneity test, and linearity test. To prove the influence of Organizational Climate variable (X1), Interpersonal Communication (X2) and Job Satisfaction (X3) on Performance (Y). In this research, used data analysis technique with path analysis.

Based on the results of the research analysis: 1) There is influence Organizational Climate (XI) on Job Satisfaction (X3) of 0.175 ; 2) There is the influence of Interpersonal Communication (X2) on Job Satisfaction (X3) of 0.35; 3) There is an effect of Organizational Climate (XI) on Performance (Y) of 0.293; 4) There is the influence of Interpersonal Communication (X2) on Performance (Y) of 0.259; 5) There is influence of Job Satisfaction (X3) on Performance (Y) of 0.254. Performance

Keywords: Organizational Climate, Interpersonal Communication, Job Satisfaction and
\end{abstract}

\section{PENDAHULUAN}

Sumber Daya Manusia (SDM) merupakan komponen utama dalam suatu organisasi sebagai perencana dan penggerak aktivitas organisasi. dalam rangka mencapai tujuan yang telah ditetapkan organisasi. Oleh karena itu kualitasnya harus terus ditingkatkan dimana kualitas Sumber Daya Manusia merupakan inventaris yang sangat penting bagi organisasi.

Dengan adanya SDM yang berkualitas diharapkan kinerja karyawan meningkat sehingga tujuan organisasi dapat tercapai. Kinerja pegawai yang optimal tercapai tidak terlepas dari faktor-faktor yang mempengaruhi. Antara lain Iklim organisasi, komunikasi interpersonal dan kepuasan kerja.
Iklim organisasi terkait erat dengan proses penciptaan lingkungan kerja yang kondusif, agar tercipta hubungan dan kerja sama yang harmonis diantara para pegawai. Iklim organisasi penting untuk diciptakan karena merupakan persepsi seseorang tentang apa yang diberikan oleh organisasi dan dijadikan dasar bagi penentuan tingkah laku anggota selanjutnya. Setiap organisasi memiliki iklim organisasi yang berbeda.

Komunikasi dalam organisasi sangat penting untuk menciptakan persamaan pengertian, pola pemikiran, dan sikap/tingkah laku dalam rangka mencapai tujuan bersama. Komunikasi interpersonal dilakukan dengan tujuan agar antara komunikator dan komunikan mempunyai kesamaan dan kesepakatan pesan sehingga menimbulkan suatu pengertian. Karena 
sifatnya yang dialogis maka dalam komunikasi interpersonal diperlukan seorang komunikator yang handal yang memiliki keahlian dalam berkomunikasi (communication skill) yang dapat mengkomunikasikan pesan yang hendak disampaikan, agar komunikan memahami/mengerti terhadap pesan yang diterima.

Kepuasan kerja (job satisfaction) merupakan perasaan senang terhadap apa yang telah dikerjakannya. Kepusaan kerja merupakan hal yang sulit diukur dan sifatnya subjektif. Hal ini disebabkan karena setiap orang mempunyai keinginan yang berbedabeda dan ingin dipenuhi. Seorang pegawai dapat dikatakan puas dalam bekerja jika dapat melakukan pekerjaannya dengan baik dan yang diharapkan dapat diperoleh sesuai dengan yang diinginkan atau bahkan lebih

Mengacu pada penelitian yang dilakukan oleh Michael D Reiner, yang meneliti tentang kepuasan Personel US Air Force di Langley Air Force Base menyimpulkan bahwa kepuasan kerja berpengaruh terhadap kinerja personel angkatan udara Amerika Serikat, dengan hasil 64,1 persen kepuasan kerja berhubungan dengan dengan kinerja, 18,0 persen kepuasan dengan fungsi pengawasan, dan 24,9 persen kepuasan dengan rekan kerja.

Pada lembaga pemerintah seperti TNI Angkatan Udara juga menuntut adanya kinerja yang baik dari anggotanya. Dalam rangka mewujudkan "the first class air force", maka TNI Angkatan Udara terus berupaya meningkatkan kualitas personelnya yaitu dengan memberdayakan seluruh prajurit agar dapat bekerja secara optimal, efektif, efisien dan profesional.

Salah satu Komando Utama TNI AU yang mengelola pendidikan dan bertugas meningkatkan mutu personel TNI AU adalah Komando Pembinaan Doktrin dan Latihan TNI Angkatan Udara (Kodiklatau). Kodiklatau adalah Komando Utama Pembinaan TNI AU yang berkedudukan langsung dibawah Kepala Staf TNI Angkatan Udara. Kodiklatau mempunyai tugas menyelenggarakan pendidikan pertama, pembentukan, pengembangan, spesialisasi, peralihan, dan pendidikan lain guna meningkatkan mutu personel TNI Angkatan Udara serta menyelenggarakan pengembangan sistem pendidikan, didaktik, metodik pendidikan, dan ilmu pengetahuan kedirgantaraan serta pembinaan potensi dirgantara.

Untuk mencapai kinerja yang maksimal dan mengatasi permasalahan tersebut di atas maka beberapa upaya yang dapat dilakukan antara lain : memberikan pendidikan/keterampilan/pengalaman di tempat kerja ( learning by doing/on the job training/bekerja sambil belajar ), memberikan tauladan kepada anggota melalui sikap dan kerja nyata, pemberian 
reward dan punishment yang sesuai, mengoptimalkan jam komandan yaitu dengan pemberian santiaji/penjelasan/pengarahan terhadap anggota secara rutin tentang hal-hal yang boleh dan tidak boleh dilakukan oleh prajurit, membangun sistem komunikasi yang lebih terbuka yaitu dengan cara membuat kegiatankegiatan yang sifatnya informal (contoh; olahraga bersama, family gathering atau kegiatan-kegiatan lain yang melibatnya personel dari semua tingkat kepangkatan).

Dengan adanya persepsi, teori-teori dan permasalahan yang telah dikemukakan di atas, maka penulis tertarik dan mencoba untuk meneliti hubungan dan pengaruh iklim organisasi, komunikasi interpersonal, kepuasan kerja dan kinerja

\section{RUMUSAN MASALAH}

Berdasarkan identifikasi masalah dan pembatasan masalah yang telah diuraikan di atas, maka penulis merumuskan permasalahan sebagai dalam penelitian ini sebagi berikut:

1. Apakah iklim organisasi berpengaruh terhadap kepuasan kerja di Kodiklatau?

2. Apakah komunikasi interpersonal berpengaruh terhadap kepuasan kerja di Kodiklatau?

3. Apakah iklim organisasi berpengaruh terhadap kinerja di Kodiklatau?
4. Apakah komunikasi interpersonal berpengaruh terhadap kinerja di Kodiklatau?

5. Apakah kepuasan kerja berpengaruh terhadap kinerja di Kodiklatau?

\section{Kinerja}

Banyak batasan yang diberikan para ahli mengenai istilah kinerja, meskipun ada perbedaan namun secara prinsip kinerja adalah mengenai proses pencapaian hasil kerja. Istilah kinerja berasal dari kata job performance atau actual performance (prestasi kerja atau prestasi sesungguhnya yang dicapai oleh seseorang).

Menurut Peter Jennergen pengertian kinerja organisasi adalah "Organizational performance is a level that shows how far the execution of tasks can be executed in actual and organizational mission is achieved" tingkat yang menunjukan seberapa jauh pelaksanaan tugas dapat dijalankan secara aktual dan misi organisasi tercapai". Kinerja merupakan hasil dari pelaksanaan tugas yang dilakukan oleh seorang karyawan berdasarkan tanggung jawab yang dibebankan kepadanya yang dipengaruhi oleh kecakapan, keterampilan, pengalaman dan kesungguhan kerja dari karyawan.

\section{Indikator Kinerja}

Ukuran secara kualitatif dan kuantitatif yang menunjukkan tingkatan pencapaian suatu sasaran atau tujuan yang telah ditetapkan adalah merupakan sesuatu yang dapat dihitung serta digunakan sebagai dasar 
untuk menilai atau melihat bahwa kinerja setiap hari dalam perusahaan dan perseorangan terus mengalami peningkatan sesuai dengan rencana yang telah ditetapkan.

Sedangkan menurut Mathis dan Jackson indikator kinerja meliputi :

1. Kuantitas Kerja.

Standar ini dilakukan dengan cara membandingkan antara besarnya volume kerja yang seharusnya (standar kerja norma ) dengan kemampuan sebenarnya.

2. Kualitas Kerja.

Standar ini menekankan pada mutu kerja yang dihasilkan dibandingkan volume kerja.

3. Pemanfaatan Waktu.

Adalah penggunaan masa kerja yang disesuaikan dengan kebijaksanaan perusahaan.

4. Tingkat Kehadiran.

Asumsi yang digunakan dalam standar ini adalah jika kehadiran pegawai di bawah standar kerja yang ditetapkan maka pegawai tersebut tidak akan mampu memberikan kontribusi yang optimal bagi organisasi/perusahaan.

5. Kerja sama.

Stephen Robbins mengatakan bahwa Indikator adalah untuk mengukur kinerja karyawan secara individu ada lima, yaitu :

1. Kualitas. Kualitas kerja diukur dari persepsi karyawan terhadap kualitas pekerjaan yang dihasilkan serta kesempurnaan tugas terhadap keterampilan dan kemampuan karyawan.

2. Kuantitas. Merupakan jumlah yang dihasilkan dinyatakan dalam istilah seperti jumlah unit, jumlah siklus aktivitas yang diselesaikan

3. Ketepatan waktu. Merupakan tingkat aktivitas diselesaikan pada awal waktu yang dinyatakan, dilihat dari sudut koordinasi dengan hasil output serta memaksimalkan waktu yang tersedia untuk aktivitas lain.

4. Efektivitas. Merupakan tingkat penggunaan sumber daya organisasi (tenaga, uang, teknologi, bahan baku) dimaksimalkan dengan maksud menaikkan hasil dari setiap unit dalam penggunaan sumber daya.

5. Kemandirian. Merupakan suatu tingkat dimana karyawan mempunyai komitmen kerja dengan instansi dan tanggung jawab karyawan terhadap kantor.

Indikator Kinerja dalam penelitian ini adalah sebagai berikut: (1) Kualitas kerja, yang mencakup pendidikan/ pelatihan, etos kerja, sikap mental dan kondisi fisik (2) Kuantitas kerja, yang meliputi volume keluaran dan kontribusi yang diberikan pegawai terhadap organisasi (3) Kerjasama, yaitu kerjasama antara atasan dan bawahan dan keterlibatan seluruh pegawai Pemanfaatan waktu, yaitu penggunaan waktu 
kerja yang disesuaikan (5) Tingkat kehadiran, meliputi standar kehadiran (6) Sarana pendukung, meliputi keselamatan kerja, kesehatan kerja, sarana kerja, teknologi

\section{Iklim Organisasi}

Organisasi dapat dikatakan mempunyai iklim yang baik bila karyawannya dapat merasakan lingkungan kerja yang menyenangkan. Dengan lingkungan kerja yang menyenangkan maka akan tercipta iklim organisasi yang baik dan pada akhirnya menimbulkan penilaian yang positif pada organisasi itu sendiri.

Menurut Allen mengatakan bahwa iklim organisasi adalah persepsi pegawai mengenai kualitas lingkungan internal organisasi yang secara relatif dirasakan oleh anggota organisasi yang kemudian akan mempengaruhi perilaku mereka berikutnya.

Selanjutnya dikemukakan oleh Simamora bahwa iklim organisasi adalah lingkungan internal atau psikologi organisasi. Iklim organisasi mempengaruhi praktik dan kebijakan SDM yang diterima oleh anggota organisasi. Perlu diketahui bahwa setiap organisasi akan memiliki iklim organisasi yang berbeda. Keanekaragaman pekerjaan yang dirancang di dalam organisasi, atau sifat individu yang ada akan menggambarkan perbedaan tersebut. Perbedaan iklim organisasi pada setiap organisasi ditentukan oleh karakter individu yang menjalankan roda organisasi yang selanjutnya dapat mempengaruhi kinerja pegawai.

$\begin{array}{lrr}\text { Sedangkan menurut } & \begin{array}{c}\text { Stinger } \\ \text { "collection }\end{array} \\ \text { mendefenisikan iklim sebagai } & \text { colnt } \\ \text { and pattern of environmental determinant of } \\ \text { aroused motivation", iklim organisasi adalah } \\ \text { koleksi dan pola } & \text { lingkungan } & \text { yang } \\ \text { menentukan munculnya } & \text { motivasi. } & \text { Jadi } \\ \text { motivasi kerja } & \text { pegawai } & \text { dapat } \\ \text { terbangun/tumbuh } & \text { tergantung } & \text { dari }\end{array}$
lingkungan yang mempengaruhi seberapa besar lingkungan dapat merubah motivasi pegawai.

Iklim organisasi adalah persepsi mengenai lingkungan internal organisasi (kebijakan organisasi, kepemimpinan, suasana kerja, sarana prasarana pendukung kerja) yang dirasakan oleh anggota organisasi yang dapat mempengaruhi sikap, perilaku dan motivasi pegawai dalam bekerja dan selanjutnya menentukan kinerja organisasi.

Indikator dari Iklim organisasi dalam penelitian ini adalah sebagai berikut: (1) Struktur, yang mencakup peraturan, prosedur, tujuan dan nilai-nilai organisasi (2) Tanggung jawab, meliputi pengawasan, pengarahan/bimbingan (3) Penghargaan, meliputi pengakuan, kritikan, dan pemberian kesempatan berkembang (4) Keramahan, meliputi suasana kerja yang bersahabat dan hubungan baik dengan rekan kerja (5) Dukungan, meliputi perasaan saling mendukung/saling membutuhkan antara atasan dan bawahan (6) Identitas organisasi dan kesetiaan, meliputi kesetiaan, komitmen 
dan perasaan bangga pada organisasi (7) Resiko, yaitu keberanian mengambil resiko.

\section{Komunikasi interpersonal}

Komunikasi merupakan mekanisme yang menyebabkan adanya hubungan antar manusia di dalam masyarakat atau kelompok, dengan menggunakan lambang-lambang yang mengandung makna dan dapat dilakukan untuk menembus ruang dan menyimpannya dalam dimensi waktu. Komunikasi juga dapat didefinisikan sebagai penyampaian informasi antara dua orang atau lebih. Komunikasi merupakan suatu proses yang vital dalam organisasi karena komunikasi diperlukan bagi efektifitas kepemimpinan, perencanaan, pengendalian, koordinasi, latihan, manajemen konflik, serta proses-proses organisasi lainnya. Komunikasi interpersonal didefinisikan sebagai komunikasi utama dan menggambarkan peserta yang saling bergantungan satu sama lain dan memiliki sejarah bersama. Hal ini dapat melibatkan suatu percakapan atau individu berinteraksi dengan banyak orang dalam masyarakat. Ini membantu kita memahami bagaimana dan mengapa orang berperilaku dan berkomunikasi dengan cara yang berbeda untuk membangun dan menegosiasikan realitas sosial.

Sedangkan menurut Devito (dalam Effendy) mengatakan bahwa "Interpersonal communication is the delivery of a message by one person and the reception of a message by another person or a small group of people, with its effects and with the opportunity to provide immediate feedback". Komunikasi interpersonal adalah penyampaian pesan oleh satu orang dan penerimaan pesan oleh orang lain atau sekelompok kecil orang dengan pengaruhnya dengan kesempatan untuk memberikan umpan balik segera.

Everett M. Rogers (dalam Deddy Mulyana) menyatakan bahwa, "Communication is the process by which an idea is transferred from source to a recipient or more, with a view to changing their behavior". Komunikasi adalah proses dimana suatu ide dialihkan dari sumber komunikasi interpersonal adalah komunikasi antara orang-orang atau antar pribadi secara tatap muka yang memungkinkan setiap pesertanya menangkap reaksi orang lain secara langsung dan mendapatkan umpan balik dengan segera. Komunikasi interpersonal dilakukan secara verbal maupun nonverbal yang dapat mengubah pola pikir, sikap, pendapat atau perilaku seseorang.

Indikator dari Komunikasi interpersonal dalam penelitian ini adalah sebagai berikut : (1) Openness; meliputi kedekatan, kemauan, kebebasan, (2) Perilaku positif (positiviness); meliputi perhatian yg positif terhadap orang lain, perasaan positif terhadap pekerjaan, perasaan positif terhadap lingkungan, (3) Empati (empathy); yaitu merasakan perasaan yang sama terhadap 
orang lain, memahami posisi orang lain, memberi penilaian benar/salah kepada orang lain

(4) Perilaku suportif (supportiveness); yaitu perilaku destruktif, spontanitas, provisionalime (5) Kesamaan (equality); meliputi keseimbangan/kesamaan pengalaman dan kesamaaan dalam percakapan.

\section{Kepuasan kerja}

Salah satu hal penting pada sumber daya manusia dalam suatu organisasi adalah terciptanya kepuasan kerja pegawai. Kepuasan menunjukkan kemampuan organisasi dalam memenuhi kebutuhan karyawannya. Pengertian kepuasan dikemukakan oleh beberapa ahli diantaranya adalah Robbins dan Judge mendefinisikan "Job satisfaction as a positive feeling about one's work which is the result of an evaluation of its characteristics". (kepuasan kerja sebagai suatu perasaan positif tentang pekerjaan seseorang yang merupakan hasil dari evaluasi karakteristik-karakteristiknya). Pegawai yang memiliki sikap positif terhadap pekerjaannya akan lebih mudah mewujudkan kepuasan kerja yang selanjutnya dapat meningkatkan kinerjanya.

Moorse (dalam Panggabean), mengemukakan bahwa pada dasarnya " $J o b$ satisfaction depends on what an employee wants from his job and what they earn". (kepuasan kerja tergantung kepada apa yang diinginkan oleh seorang karyawan dari pekerjaannya dan apa yang mereka peroleh).
Karyawan yang paling merasa tidak puas adalah mereka yang mempunyai keinginan paling banyak dan mendapat paling sedikit. Sedangkan yang merasa paling puas adalah mereka yang menginginkan banyak dan mendapatkannya.

Menurut Keith David dan John Newstorm mengatakan "Job satisfaction is a set of employee feelings about the fun or the employment of employees". Kepuasan kerja adalah seperangkat perasaan pegawai tentang menyenangkan atau tidaknya pekerjaan karyawan). Kepuasan kerja ditandai dengan adanya perasaan pegawai dapat menyenangi pekerjaan yang menjadi tanggung jawabnya.

Sedangkan menurut Handoko mengatakan "kepuasan kerja adalah keadaan emosional yang menyenangkan atau tidak menyenangkan dimana para karyawan memandang pekerjaan mereka". Perasaan tersebut merupakan cermin dari penyesuaian antara apa yang diperoleh dengan apa yang diharapkan. Dengan mendapatkan apa yang diinginkan bahkan lebih maka dapat dikatakan seorang pegawai merasa telah memperoleh kepuasan dalam pekerjaan.

Indikator dari Kepuasan kerja dalam penelitian ini adalah sebagai berikut: (1) Monetery/non-monetery ; meliputi gaji, upah dan promosi (2) Karakteristik Pekerjaan; meliputi penilaian tugas pegawai, keanekaragaman keterampilan dan pandangan pegawai terhadap pekerjaan (3) Karakteristik kerja; meliputi tingkat 
kesulitan, sarana prasarana dan kondisi lingkungan (4) Karakteristik Individu; meliputi sikap, perilaku dan nilai-nilai dalam organisasi.

\section{KERANGKA BERPIKIR}

Berdasarkan dari Grand Theory dan kerangka berpikir tersebut di atas, maka dapat diduga bahwa terdapat pengaruh yang positif dan signifikan antara Iklim organisasi, Komunikasi interpersonel dan Kepuasan Kerja terhadap Kinerja. Pengaruh masing-masing variabel dapat diuraikan seperti tersebut di bawah ini:

1. Pengaruh Iklim organisasi $\left(X_{1}\right)$ terhadap Kepuasan Kerja $\left(\mathrm{X}_{3}\right)$

Kepuasan kerja karyawan harus diciptakan sebaik-baiknya supaya moral kerja, dedikasi, kecintaan, dan kedisiplinan karyawan meningkat.

Berkaitan dengan kepuasan kerja, iklim organisasi merupakan suatu keadaan yang menggambarkan suatu lingkungan psikologis organisasi yang dirasakan oleh semua anggota organisasi tersebut.

Sehingga iklim organisasi juga sangat dipengaruhi oleh persepsi anggota.

2. Pengaruh

Komunikasi interpersonal $\left(\mathrm{X}_{2}\right)$ terhadap Kepuasan $\operatorname{Kerja}\left(\mathrm{X}_{3}\right)$

Kepuasan kerja karyawan dipengaruhi oleh beberapa faktor, salah satu diantaranya adalah rekan kerja yang mendukung. Kepuasan kerja dapat terbentuk jika sesama karyawan saling mendukung dan bekerjasama dengan baik. Dukungan sosial dapat dimunculkan karyawan dengan cara melakukan komunikasi interpersonal. Komunikasi interpersonal yang dilakukan didalam organisasi sifatnya dialogis yang dapat mengubah pola pikir, sikap, pendapat atau perilaku seseorang, menuju ke arah yang lebih baik sesuai dengan harapan organisasi.

3. Pengaruh Iklim organisasi $\left(X_{1}\right)$ terhadap Kinerja (Y)

Kinerja merupakan hasil dari pelaksanaan tugas yang dilakukan oleh seorang karyawan berdasarkan tanggung jawab yang dibebankan kepadanya yang dipengaruhi oleh kecakapan, keterampilan, pengalaman dan kesungguhan kerja dari karyawan. Oleh karena itu kemampuan personel harus terus ditingkatkan. Untuk meningkatkan kemampuan personel maka harus didukung oleh iklim organisasi yang baik yang mencakup kebijakan, kepemimpinan, sarana dan prasarana yang mendukung.

4. Pengaruh Komunikasi interpersonal $\left(\mathrm{X}_{2}\right)$ terhadap Kinerja (Y)

Komunikasi interpersonal merupakan komunikasi yang dilakukan oleh beberapa orang secara tatap muka. Karena sifatnya yang dialogis maka dapat memberikan umpan balik dengan segera kepada semua individu yang terlibat. Keefektifan dalam 
komunikasi yang dipengaruhi oleh kemampuan komunikasi dari pengirim dan penerima pesan serta kekayaan informasi, akan berdampak pada kinerja pegawai.

5. Pengaruh Kepuasan Kerja $\left(X_{3}\right)$ terhadap Kinerja (Y)

Kepuasan kerja adalah sikap emosional yang menyenangkan dan mencintai pekerjannya. Sikap ini dicerminkan oleh moral kerja, kedisiplinan, dan prestasi kerja. Apabila kepuasan kerja terjadi maka karyawan menunjukkan sikap positif terhadap segala pekerjaan yang menjadi tugasnya dalam lingkungan kerja. Karyawan yang mempunyai kepuasan kerja yang tinggi mampu melakukan pekerjaan dengan baik dan ingin mencapai hasil maksimal dalam pekerjaannya

Model Hipotesis dalam penelitian dapat dililhat pada gambar di bawah ini:

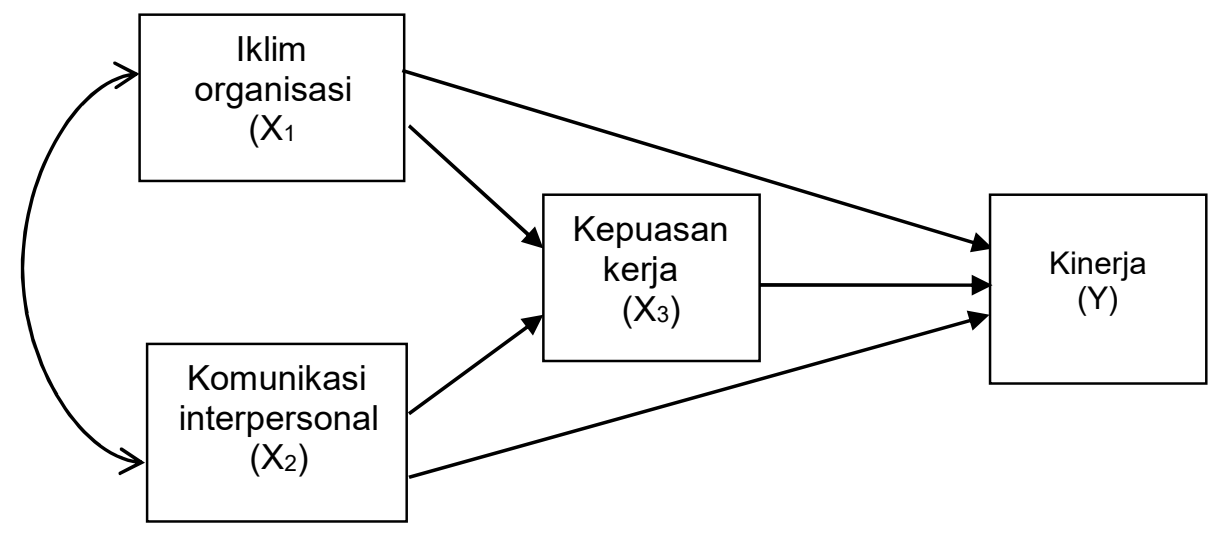

\section{HIPOTESIS PENELITIAN}

Berdasarkan deskripsi teoritik dan kerangka berpikir di atas, dalam penelitian ini diajukan hipotesis sebagai berikut :

1. Terdapat pengaruh Iklim organisasi terhadap kepuasan kerja di Kodiklatau.

2. Terdapat pengaruh komunikasi interpersonal terhadap kepuasan kerja di Kodiklatau.

3. Terdapat pengaruh iklim organisasi terhadap kinerja di Kodiklatau.
4. Terdapat pengaruh komunikasi interpersonal terhadap kinerja di Kodiklatau.

5. Terdapat pengaruh kepuasan kerja terhadap kinerja di Kodiklatau. 


\section{PEMBAHASAN}

\section{Correlations}

\begin{tabular}{|c|c|c|c|c|c|}
\hline & & $\begin{array}{l}\text { IKLIM } \\
\text { ORGANISASI }\end{array}$ & $\begin{array}{l}\text { KOMUNIKAS } \\
\text { I INTERPER- } \\
\text { SONAL }\end{array}$ & $\begin{array}{l}\text { KEPUASAN } \\
\text { KERJA }\end{array}$ & KINERJA \\
\hline \multirow[t]{3}{*}{ IKLIM ORGANISASI } & Pearson Correlation & 1 & $.780^{* *}$ & $.695^{* *}$ & $.812^{* *}$ \\
\hline & Sig. (2-tailed) & & .000 & .000 & .000 \\
\hline & $\mathrm{N}$ & 96 & 96 & 96 & 96 \\
\hline \multirow{3}{*}{$\begin{array}{l}\text { KOMUNIKASI } \\
\text { INTERPERSONAL }\end{array}$} & Pearson Correlation & $.780^{* *}$ & 1 & $.742^{* *}$ & $.819^{* *}$ \\
\hline & Sig. (2-tailed) & .000 & & .000 & .000 \\
\hline & $\mathrm{N}$ & 96 & 96 & 96 & 96 \\
\hline \multirow[t]{3}{*}{ KEPUASAN KERJA } & Pearson Correlation & $.695^{* *}$ & $.742^{* *}$ & 1 & $.790^{* *}$ \\
\hline & Sig. (2-tailed) & .000 & .000 & & .000 \\
\hline & $\mathrm{N}$ & 96 & 96 & 96 & 96 \\
\hline \multirow[t]{3}{*}{ KINERJA } & Pearson Correlation & $.812^{* *}$ & $.819^{* *}$ & $.790^{* *}$ & 1 \\
\hline & Sig. (2-tailed) & .000 & .000 & .000 & \\
\hline & $\mathrm{N}$ & 96 & 96 & 96 & 96 \\
\hline
\end{tabular}

**. Correlation is significant at the 0.01 level (2-tailed).

Tabel Perhitungan Koefisien Korelasi Dari tabel diatas, diperoleh data antar Variabel nilai korelasi antar variabel seperti tercantum pada table di bawah:

\begin{tabular}{|l|l|l|}
\hline $\begin{array}{l}\text { Koefisien Korelasi } \\
\text { Antar Variabel }\end{array}$ & Simbol & Nilai \\
\hline $\mathrm{X}_{1}$ dan $\mathrm{X}_{2}$ & $\mathrm{r}_{12}$ & 0,780 \\
\hline $\mathrm{X}_{1}$ dan $\mathrm{X}_{3}$ & $\mathrm{r}_{13}$ & 0,695 \\
\hline $\mathrm{X}_{2}$ dan $\mathrm{X}_{3}$ & $\mathrm{r}_{23}$ & 0,742 \\
\hline $\mathrm{X}_{1}$ dan $\mathrm{Y}$ & $\mathrm{r}_{14}$ & 0,812 \\
\hline $\mathrm{X}_{2}$ dan $\mathrm{Y}$ & $\mathrm{r}_{24}$ & 0,819 \\
\hline $\mathrm{X}_{3}$ dan $\mathrm{Y}$ & $\mathrm{r}_{34}$ & 0,790 \\
\hline
\end{tabular}

Hubungan kausal antar variabel Interpersonal $\left(\mathrm{X}_{2}\right)$ persamaan struktural subpada sub-struktur 1 yang ditampilkan pada struktur 1 adalah $\mathrm{X}_{1}=\rho_{31} \mathrm{X}_{1}+\rho_{32} \mathrm{X}_{2}+\varepsilon_{1}$ gambar 4.6 terdiri dari 1 (satu ) variabel Hasil pengolahan data pada Sub-Struktur 1 endogen yaitu Kepuasan Kerja $\left(\mathrm{X}_{3}\right)$ dan 2 (dua) variabel eksogen yaitu Iklim menggunakan SPSS 24 disajikan sebagai Organisasi $\quad\left(\mathrm{X}_{1}\right) \quad$ dan $\quad$ Komunikasi 


\section{Coefficients $^{\mathrm{a}}$}

\begin{tabular}{|c|c|c|c|c|c|c|}
\hline \multirow[b]{2}{*}{ Model } & & \multicolumn{2}{|c|}{$\begin{array}{l}\text { Unstandardized } \\
\text { Coefficients }\end{array}$} & \multirow{2}{*}{$\begin{array}{l}\text { Standardized } \\
\text { Coefficients } \\
\text { Beta }\end{array}$} & \multirow[b]{2}{*}{$\mathrm{T}$} & \multirow[b]{2}{*}{ Sig. } \\
\hline & & $\mathrm{B}$ & Std. Error & & & \\
\hline \multirow[t]{3}{*}{1} & (Constant) & 8.180 & 8.239 & & .993 & .323 \\
\hline & KOMUNIKASI INTERPERSONAL & .610 & .127 & .512 & 4.794 & .000 \\
\hline & IKLIM ORGANISASI & .319 & .116 & .295 & 2.760 & .007 \\
\hline
\end{tabular}

a. Dependent Variable: KEPUASAN KERJA

\section{Tabel Perhitungan Koefisien Jalur}

Model 1 : Summary $\mathrm{X}_{1}$, dan $\mathrm{X}_{2}$ tehadap $\mathrm{X}_{3}$

\section{Model Summary}

\begin{tabular}{ll|l|l|l} 
Model & R & R Square & Adjusted R Square & Std. Error of the Estimate \\
\hline 1 & $.765^{\mathrm{a}}$ & .585 & .576 & 8.51243 \\
\hline
\end{tabular}

a. Predictors: (Constant), IKLIM ORGANISASI, KOMUNIKASI INTERPERSONAL

\section{Tabel Model Summary Model 1-Sub Struktr 1}

Model 1 : Anova $\mathrm{X}_{1}$, dan $\mathrm{X}_{2}$ tehadap $\mathrm{X}_{3}$

\begin{tabular}{|c|c|c|c|c|c|c|}
\hline \multicolumn{7}{|c|}{ ANOVA $^{\mathrm{a}}$} \\
\hline Model & & Sum of Squares & Df & Mean Square & $\mathrm{F}$ & Sig. \\
\hline \multirow[t]{3}{*}{1} & Regression & 9501.235 & 2 & 4750.618 & 65.561 & $.000^{\mathrm{b}}$ \\
\hline & Residual & 6738.921 & 93 & 72.462 & & \\
\hline & Total & 16240.156 & 95 & & & \\
\hline
\end{tabular}

a. Dependent Variable: KEPUASAN KERJA

b. Predictors: (Constant), IKLIM ORGANISASI, KOMUNIKASI INTERPERSONAL

\section{Tabel Annova Model 1-Sub Struktr 1}

Dari tabel dapat dilihat bahwa koefisien jalur $\mathrm{X}_{1}$, ke $\mathrm{X}_{2}$ atau $\rho_{31}=0,295$ dan koefisien jalur $\mathrm{X}_{2}$ ke $\mathrm{X}_{3}$ atau $\rho_{32}=0,512$ maka persamaan jalur pada sub-struktur 1 adalah $\mathrm{X}_{3}=0,295 \mathrm{X}_{1}+0,512 \mathrm{X}_{2}+\varepsilon_{1}$

Tabel menunjukkan nilai $\mathrm{R}^{2} \mathrm{x}_{3}\left(\mathrm{x}_{1}, \mathrm{x}_{2}\right)=0$, 585, sehingga koefisien residu dapat dihitung dengan menggunakan rumus ${ }_{3} \varepsilon=\sqrt{1-R_{X_{3}\left(X_{1} X_{2}\right)}^{2}}=0,644$ sehingga koefisien residu $\rho \mathrm{X}_{3} \varepsilon=\sqrt{1-0,585}=$ 0,644 . Setelah koefisien jalur diketahui, maka persamaan jalur pada sub-struktur 1 menjadi $X_{3}=0,295 X_{1}+0,512 X_{2}+0,644$

Pengujian keberartian koefisien jalur secara parsial pada Sub- Struktur 1 dapat dilakukan dengan melihat tabe.l Dari hasil perhitungan diperoleh data yang dapat dilihat pada tabel sebagai berikut:

\section{Tabel Hasil Pengujian Keberartian Koefisien Jalur Sub-Struktur 1}




\begin{tabular}{|c|l|l|l|l|}
\hline Jalur & $\begin{array}{l}\text { Koefisien } \\
\text { Jalur }\end{array}$ & $\mathbf{t}_{\text {hitung }}$ & $\mathbf{t}_{\text {tabel }}$ & Hasil Uji \\
\hline$\rho_{31}$ & 0,295 & 2,760 & 1,984 & Signifikan \\
\hline$\rho_{32}$ & 0,512 & 4,794 & 1,984 & Signifikan \\
\hline
\end{tabular}

Dari tabel diketahui bahwa nilai hitung Sig. lebih kecil dari pada tingkat $\alpha$ yang digunakan (yaitu 0.05) atau 0,000<0.05 dan nilai $F_{\text {hitung }}(65.561)>F_{\text {tabel }}(0,323)$. sehingga $\mathrm{H}_{0}$ ditolak, artinya terdapat pengaruh yang berarti atau signifikan antara Iklim Organisasi $\left(\mathrm{X}_{1}\right)$ Komunikasi Interpersonal $\left(\mathrm{X}_{2}\right)$ terhadap Kepuasan Kerja $\left(\mathrm{X}_{3}\right)$.

\section{Perhitungan Besar Pengaruh pada}

\section{Sub - Struktur 1}

Untuk mengetahui besarnya pengaruh yang diterima oleh sebuah Variabel endogen dari dua buah variabel endogen. dapat secara parsial (langsung maupun tidak langsung melalui varibel eksogen lain ) maupun secara bersama-sama

a. Menghitung pengaruh langsung, pengaruh tidak langsung serta pengaruh total variabel Iklim Organisasi $\left(\mathrm{X}_{1}\right)$, terhadap variabel Komunikasi Interpersonal $\left(\mathrm{X}_{2}\right)$ secara parsial, sebagai berikut:

1) Besarnya pengaruh langsung variabel $\mathrm{X}_{1}$ terhadap variabel $\mathrm{X}_{3}$

$=\left(\rho_{31}\right)^{2}=(0,295)^{2}=0,087$

2) Besarnya pengaruh tidak langsung variabel $X_{1}$ terhadap variabel $X_{3}$

melalui $\mathrm{X}_{2}$

$$
\begin{aligned}
& =\rho_{31} \times R_{X_{3}\left(X_{1} X_{2}\right)} \times \rho_{32}=0,295 \times 0,585 \\
& \text { × } 0,512=0,088
\end{aligned}
$$

3) Besarnya pengaruh total variabel $X_{1}$ terhadap variabel $\mathrm{X}_{3}$

$$
\begin{aligned}
= & \left(\rho_{31}\right)^{2}+\rho_{31} \times R_{X_{3}\left(X_{1} X_{2}\right)} \quad \mathrm{x} \rho_{32}= \\
& 0,087+0,088=0,175
\end{aligned}
$$

Kesimpulannya pengaruh variabel Iklim Organisasi $\left(\mathrm{X}_{1}\right)$ terhadap variabel Kepuasan $\left(\mathrm{X}_{3}\right)$ adalah sebesar 0,175 hal ini berarti Kepuasan Kerja ditentukan oleh Iklim Organisasi sebesar 0,175 .

b. Menghitung pengaruh langsung pengaruh tidak langsung serta pengaruh total variabel Komunikasi Interpersonal $\left(\mathrm{X}_{2}\right)$ terhadap variabel Kepuasan Kerja $\left(\mathrm{X}_{3}\right)$ secara parsial, sebagai berikut:

1) Besarnya pengaruh langsung variabel $\mathrm{X}_{2}$ terhadap variabel $\mathrm{X}_{3}$

$=\left(\rho_{32}\right)^{2}=(0,512)^{2}=0,262$

2) Besarnya pengaruh tidak langsung variabel $\mathrm{X}_{2}$ terhadap variabel $\mathrm{X}_{3}$ melalui $\mathrm{X}_{1}$

$=\rho_{32} \times R_{X_{3}\left(X_{1} X_{2}\right)} \times \rho_{31}=0,512 \times 0,585$ x $0,295=0,088$

3) Besarnya pengaruh total variabel $X_{2}$ terhadap variabel $\mathrm{X}_{3}$

$=\left(\rho_{32}\right)^{2}+\rho_{32} \times R_{X_{3}\left(X_{1} X_{2}\right)} \times \rho_{31}=$ $0,262+0,088=0,35$

Kesimpulannya pengaruh variabel Komunikasi Interpersonal $\left(\mathrm{X}_{2}\right)$ terhadap 
variable Kepuasan Kerja $\left(\mathrm{X}_{3}\right)$ adalah sebesar 0,35 hal ini berarti Kepuasan Kerja

4. Perhitungan koefisien Jalur pada

Sub - Struktur 2

Hubungan kausal antar variabel pada sub-struktur 2 yang ditampilkan, terdapat 1 (satu) variabel endogen yaitu Kinerja (Y) dan 3 (tiga) variabel eksogen yaitu Iklim Organisasi $\left(\mathrm{X}_{1}\right), \quad$ Komunikasi Interpersonal $\left(\mathrm{X}_{2}\right)$, dan Kepuasan Kerja $\left(\mathrm{X}_{3}\right)$. Persamaan struktural di Sub-Struktur ditentukan oleh Komunikasi Interpersonal sebesar 0,35
2 adalah $\mathrm{Y}==\rho_{41} \mathrm{X}_{1}+\rho_{42} \mathrm{X}_{2}+\rho_{43} \mathrm{X}_{3}+\varepsilon_{1}$ pengolahan data pada sub struktur 2 menggunakan SPSS 24 dengan hasil sebagai berikut:

Model 1 : Koefisien $\mathrm{X}_{1}, \mathrm{X}_{2}$, dan $\mathrm{X}_{3}$ terhadap Y

\section{Coefficients $^{\mathrm{a}}$}

\begin{tabular}{|c|c|c|c|c|c|c|}
\hline \multirow[b]{2}{*}{ Model } & & \multicolumn{2}{|c|}{ Unstandardized Coefficients } & \multirow{2}{*}{$\begin{array}{l}\text { Standardized } \\
\text { Coefficients } \\
\text { Beta }\end{array}$} & \multirow[b]{2}{*}{$\mathrm{t}$} & \multirow[b]{2}{*}{ Sig. } \\
\hline & & $\mathrm{B}$ & Std. Error & & & \\
\hline \multirow[t]{5}{*}{1} & (Constant) & -11.918 & 6.304 & & -1.891 & .062 \\
\hline & KOMUNIKASI & .395 & .108 & .312 & 3.648 & .000 \\
\hline & INTERPERSONAL & & & & & \\
\hline & IKLIM ORGANISASI & .401 & .091 & .349 & 4.381 & .000 \\
\hline & KEPUASAN KERJA & .335 & .079 & .316 & 4.241 & .000 \\
\hline
\end{tabular}

a. Dependent Variable: KINERJA

\section{Tabel Perhitungan Coefficients Model 1-Sub Struktr 2}

Model 1 : Summary $\mathrm{X}_{1}, \mathrm{X}_{2}$, dan $\mathrm{X}_{3}$ terhadap $\mathrm{Y}$

\section{Model Summary}

\begin{tabular}{|c|c|c|c|c|}
\hline Model & $\mathrm{R}$ & R Square & Adjusted R Square & Std. Error of the Estimate \\
\hline 1 & $.888^{\mathrm{a}}$ & .789 & .782 & 6.47880 \\
\hline
\end{tabular}

\section{Tabel Model Summary Model 1-Sub Struktr 2}

Model 1 : Anova $\mathrm{X}_{1}, \mathrm{X}_{2}$, dan $\mathrm{X}_{3}$ terhadap $\mathrm{Y}$

ANOVA $^{\mathrm{a}}$

\begin{tabular}{lll|l|l|l|l}
\multirow{2}{*}{ Model } & \multicolumn{2}{c}{ Sum of Squares } & Df & $\begin{array}{l}\text { Mean } \\
\text { Square }\end{array}$ & F & Sig. \\
\hline 1 & Regression & 14417.940 & 3 & 4805.980 & 114.497 & $.000^{\mathrm{b}}$ \\
\cline { 2 - 8 } & Residual & 3861.685 & 92 & 41.975 & & \\
\cline { 2 - 8 } & Total & 18279.625 & 95 & & & \\
\hline
\end{tabular}

a. Dependent Variable: KINERJA 
b. Predictors: (Constant), KEPUASAN KERJA, IKLTMbePAGAdSWAMOdGOMSANbKStFuktr 2 INTERPERSONAL

Dari tabel dapat dilihat bahwa koefisien $\quad$ residu $\rho \mathrm{X}_{3} \varepsilon=\sqrt{1-0,789}=$ koefisien jalur $\mathrm{X}_{1}$, ke $\mathrm{Y}$ atau $\rho_{41}=0,349$; koefisien jalur $\mathrm{X}_{2}$ ke $\mathrm{Y}$ atau $\rho_{42}=0,312$ dan koefisien jalur $\mathrm{X}_{3}$ ke $\mathrm{Y}$ atau $\rho_{43}=0,361$, maka persamaan jalur pada Sub-struktur 2 adalah $\mathrm{Y}=0,349 \mathrm{X}_{1}+0,312 \mathrm{X}_{2}+0,316 \mathrm{X}_{3}+\varepsilon_{2}$

Tabel menunjukkan nilai $\mathrm{R}^{2} \mathrm{x}_{3}$ $\left(\mathrm{x}_{1}, \mathrm{x}_{2}\right)=0,789$. sehingga koefisien residu dapat dihitung dengan menggunakan rumus ${ }_{3} \mathcal{E}=\sqrt{1-R_{X_{3}\left(X_{1} X_{2}\right)}^{2}}=0,459$ sehingga

0,459 . Setelah koefisien jalur diketahui, maka persamaan jalur pada sub-struktur 1 menjadi $\mathrm{Y}=0,349 \mathrm{X}_{1}+0,312 \mathrm{X}_{2}+0,316 \mathrm{X}_{3}+$ 0,459

Pengujian keberartian koefisien jalur secara parsial pada Sub- Struktur 1 dapat dilakukan dengan melihat tabel Dari hasil perhitungan diperoleh data seperti pada tabel sebagai berikut:

\section{Hasil Pengujian Keberatian Koefisien Jalur Sub-Struktur 1}

\begin{tabular}{|c|l|l|l|l|}
\hline Jalur & Koefisien Jalur & $\mathbf{t}_{\text {hitung }}$ & $\mathbf{t}_{\text {tabel }}$ & Hasil Uji \\
\hline$\rho_{41}$ & 0,349 & 4,381 & 1,66 & Signifikan \\
\hline$\rho_{42}$ & 0,312 & 3,648 & 1,66 & Signifikan \\
\hline$\rho_{43}$ & 0,316 & 4,241 & 1,66 & Signifikan \\
\hline
\end{tabular}

Dari tabel diketahui bahwa nilai hitung Sig. lebih kecil dari pada tingkat $\alpha$ yang digunakan (yaitu 0.05) atau $0.000<0.05$ dan nilai $F_{\text {hitung }}(114,497)>F_{\text {tabel }}(0,323)$. sehingga $\mathrm{H}_{0}$ ditolak, artinya terdapat pengaruh yang berarti atau signifikan antara Iklim Organisasi $\left(\mathrm{X}_{1}\right), \quad$ Komunikasi Interpersonal $\left(\mathrm{X}_{2}\right)$, Kepuasan Kerja $\left(\mathrm{X}_{3}\right)$ terhadap Kinerja (Y).

\section{Perhitungan Besar Pengaruh pada}

\section{Sub-Struktur 2}

Untuk mengetahui besarnya pengaruh yang diterima oleh sebuah variabel endogen dari dua buah variabel endogen dapat secara parsial (langsung maupun tidak langsung melalui varibel eksogen lain ) maupun secara bersama-sama.

a. Menghitung pengaruh langsung, pengaruh tidak langsung serta pengaruh total variabel Iklim Organisasi $\left(\mathrm{X}_{1}\right)$, terhadap variabel Kinerja (Y) secara parsial, sebagai berikut :

1) Besarnya pengaruh langsung variabel $\mathrm{X}_{1}$ terhadap variabel $\mathrm{Y}$

$$
=\left(\rho_{41}\right)^{2}=(0,349)^{2}=0,121
$$

2) Besarnya pengaruh tidak langsung variabel $\mathrm{X}_{1}$ terhadap variabel $\mathrm{Y}$ melalui $\mathrm{X}_{2}$

$$
\begin{aligned}
& =\rho_{41} \times R_{X_{3}\left(X_{1} X_{2}\right)} \times \rho_{42}=0,349 \quad \times \\
& 0,789 \times 0,312=0,085
\end{aligned}
$$


3) Besarnya pengaruh tidak langsung variabel $\mathrm{X}_{1}$ terhadap variabel $\mathrm{Y}$ melalui $\mathrm{X}_{3}$

$$
\begin{aligned}
& =\rho_{41} \times R_{X_{3}\left(X_{1} X_{2}\right)} \times \rho_{43}=0,349 \quad \times \\
& 0,789 \times 0,316=0,087
\end{aligned}
$$

4) Besarnya pengaruh total variabel $X_{1}$ terhadap variabel $\mathrm{Y}$

$$
\begin{aligned}
& =\left(\rho_{41}\right)^{2}+\rho_{41} \times R_{X_{3}\left(X_{1} X_{2}\right)} \times \rho_{42}+ \\
& \rho_{41} \times R_{X_{3}\left(X_{1} X_{2}\right)} \times \rho_{43} \\
& =0,121+0,085+0,087=0,293
\end{aligned}
$$

Kesimpulannya pengaruh variabel Iklim Organisasi $\left(\mathrm{X}_{1}\right)$ terhadap variabel Kinerja (Y) adalah sebesar 0,293 hal ini berarti Kinerja ditentukan oleh Iklim Organisasi sebesar 0,293

b. Menghitung pengaruh langsung, pengaruh tidak langsung serta pengaruh total variabel Komunikasi Interpersonal $\left(\mathrm{X}_{2}\right)$ terhadap variabel Kinerja $(\mathrm{Y})$ secara parsial, sebagai berikut:

1) Besarnya pengaruh langsung variabel $\mathrm{X}_{2}$ terhadap variabel $\mathrm{Y}$

$$
=\left(\rho_{42}\right)^{2}=(0,312)^{2}=0,097
$$

2) Besarnya pengaruh tidak langsung variabel $\mathrm{X}_{2}$ terhadap variabel $\mathrm{Y}$ melalui $\mathrm{X}_{1}$

$$
\begin{aligned}
& =\rho_{42} \times R_{X_{3}\left(X_{1} X_{2}\right)} \times \rho_{41}=0,312 \quad \times \\
& 0,789 \times 0,349=0,085
\end{aligned}
$$

3) Besarnya pengaruh tidak langsung variabel $\mathrm{X}_{2}$ terhadap variabel $\mathrm{Y}$ melalui $\mathrm{X}_{3}$

$$
\begin{aligned}
& =\rho_{42} \times R_{X_{3}\left(X_{1} X_{2}\right)} \times \rho_{43}=0,312 \quad \times \\
& 0,789 \times 0,316=0,077
\end{aligned}
$$

4) Besarnya pengaruh total variabel $X_{2}$ terhadap variabel $Y$

$$
\begin{aligned}
& =\left(\rho_{42}\right)^{2}+\rho_{42} \times R_{X_{3}\left(X_{1} X_{2}\right)} \times \rho_{41}+ \\
& \rho_{42} \times R_{X_{3}\left(X_{1} X_{2}\right)} \times \rho_{43} \\
& =0,097+0,085+0,077=0,259
\end{aligned}
$$

Kesimpulannya pengaruh variabel Komunikasi Interpersonal $\left(\mathrm{X}_{2}\right)$ terhadap variabel Kinerja (Y) adalah sebesar 0,259 hal ini berarti Kinerja ditentukan oleh Komunikasi Interpersonal sebesar 0,259

c. Menghitung pengaruh langsung, pengaruh tidak langsung serta pengaruh total variabel Kepuasan Kerja $\left(\mathrm{X}_{3}\right)$ terhadap variabel Kinerja (Y) secara parsial, sebagai berikut:

1) Besarnya pengaruh langsung variabel $\mathrm{X}_{3}$ terhadap variabel $\mathrm{Y}$

$$
=\left(\rho_{43}\right)^{2}=(0,316)^{2}=0,099
$$

2) Besarnya pengaruh tidak langsung variabel $\mathrm{X}_{3}$ terhadap variabel $\mathrm{Y}$ melalui $\mathrm{X}_{1}$

$=\rho_{43} \times R_{X_{3}\left(X_{1} X_{2}\right)} \times \rho_{41}=0,316 \quad \mathrm{x}$ $0,789 \times 0,349=0,078$

3) Besarnya pengaruh tidak langsung variabel $\mathrm{X}_{3}$ terhadap variabel $\mathrm{Y}$ melalui $\mathrm{X}_{2}$

$=\rho_{43} \times R_{X_{3}\left(X_{1} X_{2}\right)} \times \rho_{42}=0,316 \quad \mathrm{x}$ $0,789 \times 0,312=0,077$

4) Besarnya pengaruh total variabel $X_{3}$ terhadap variabel Y

$$
\begin{aligned}
& =\left(\rho_{43}\right)^{2}+\rho_{43} \times R_{X_{3}\left(X_{1} X_{2}\right)} \times \rho_{41}+ \\
& \rho_{43} \times R_{X_{3}\left(X_{1} X_{2}\right)} \times \rho_{42} \\
& =0,099+0,078+0,077=0,254
\end{aligned}
$$

Kesimpulannya pengaruh variabel Kepuasan Kerja $\left(\mathrm{X}_{3}\right)$ terhadap variabel Kinerja (Y) adalah sebesar 0,254 hal ini 
berarti Kinerja ditentukan oleh Kepuasan Kerja sebesar 0,254.

\section{KESIMPULAN}

Berdasarkan hasil analisis data dan pembahasan hasil penelitian, maka dapat disimpulkan sebagai berikut :

1. Terdapat pengaruh langsung Iklim Organisasi terhadap Kepuasan Kerja bintara/tamtama Kodiklatau..

2. Terdapat pengaruh langsung Komunikasi Interpersonal terhadap Kepuasan Kerja bintara/tamtama Kodiklatau..

3. Terdapat pengaruh langsung Iklim Organisasi terhadap Kinerja bintara/tamtama Kodiklatau..

4. Terdapat pengaruh langsung Komunikasi Interpersonal terhadap Kinerja bintara/tamtama Kodiklatau..

5. Terdapat pengaruh langsung Kepuasan Kerja terhadap Kinerja bintara/tamtama Kodiklatau.

Dari uraian diatas, maka dapat disimpulkan bahwa kinerja secara langsung dipengaruhi oleh Iklim Organisasi, Komunikasi Interpersonal dan Kepuasan Kerja. Dengan pengaruh terbesar adalah Komunikasi Interpersonal.

\section{SARAN}

Untuk meningkatkan Kinerja di Kodiklatau maka saran yang dapat disampaikan sebagai berikut :
1. Menciptakan iklim organisasi yang semakin baik dimana personel yang satu dengan lainnya saling peduli sehingga tercipta kondisi yang mendukung pelaksanaan tugas dengan baik. Dengan suasana kerja yang nyaman, aman dan menyenangkan diharapkan dapat menumbuhkan kesadaran pada bintara/tamtama akan tugas yang menjadi tanggung jawabnya.

2. Membangun sistem komunikasi interpersonal yang efektif dan terbuka terutama komunikasi antara atasan dengan bawahan, sehingga bawahan tidak ragu atau takut untuk menyampaian ide/gagasan maupun saran kepada atasan. Diketahui bahwa organisasi militer identik dengan hierarki yang kental. Sehingga komunikasi interpersonal menjadi sangat penting dan perlu mendapat perhatian yang serius dari atasan.

3. Atasan dapat memberikan motivasi dan kesempatan kepada anggota untuk mengembangkan diri melalui pemberian kebebasan mengikuti pendidikan baik yang diselenggarakan di lingkungan TNI/TNI AU maupun di luar instansi militer. Sehingga anggota mempunyai pengetahuan yang memadai untuk meningkatkan kualitas kerjanya.

Dengan kerja yang berkualitas diharapkan dapat meningkatkan kinerjanya. Demikian juga dengan pemberian motivasi melalui pemenuhan 
kebutuhan personel dapat memberikan dorongan mental anggota agar dapat berprestasi dalam kerja.

\section{DAFTAR PUSTAKA}

Affandi, H.M. Tesis : Pengaruh Iklim Organisasi terhadap Kepuasan Kerja, Komitmen, dan Kinerja Pegawai (Studi Kasus pada Pegawai di Lingkungan Pemerintah Kota Semarang).

http://eprints.undip.ac.id/9451/1/2002 MM1261.pdf. (2002).

Al Rasyid, Harun. Statistik Sosial. Program Pasca Sarjana Universitas Padjajaran, Bandung, 2004.

Ali, Muhammad. Memahami Riset Prilaku dan Sosial. Pustaka. Cendekia Utama, Bandung, 2011.

Allen, N. J. \& J. P. Meyer. Commitment in The Workplace Theory Research and Application. Califotnia: Sage Publications. 2005

As'ad, M., Psikologi Industri : Seri Sumber Daya Manusia, Liberty, Yogyakarta, 2013.

Bill Foster dan Karen R. Seeker, "Pembinaan Untuk Meningkatkan Kinerja Karyawan, PT. Gunung Agung Tbk, Jakarta, 2010.

Colquitt A. Jason, Jeffery A. Lepine, Michael . Wesson, Organizational Behaviour, 2011

Dessler, Gary. Manajemen Sumber Daya Manusia (edisi kesepuluh). PT Indeks, Jakarta, 2010 .
Devito, Joseph A.. Komunikasi Antar Manusia, Karisma Publishing Group Pamulang-Tangerang Selatan, 2011

Hani, Handoko T. Manajemen Personalia dan Sumber Daya Manusia. BPFE : Yogyakarta, 2012.

Hasibuan, H. Malayu SP. Jakarta. Manajemen Sumber Daya Manusia. Bumi Aksara, Jakarta, 2011

Idrus, Muhammad. Metode Penelitian Ilmu Sosial Pendekatan Kualitatif dan Kuantitatif, Penerbit Erlangga, Jakarta, 2009.

Kasmadi dan Nia Siti Sunariah, Panduan Modern Penelitian Kuantitatif, Alfabeta, Bandung, 2013.

Keith dan John W. Newstrom. Human Behavior at Work: Organizational Behavior. New York: McGraw - Hill Book Company.2008

Lussier, N Robert. Human Relations in OrganizationApplications and skill Building. New York: Mc Graw Hill.2010

Mangkuprawira, S dan Vitalaya, A. 2007. Manajemen Mutu Sumber Daya Manusia. Ghalia Indonesia, Bogor. 2007

Mathis, Robert L. dan John H. Jackson. Manajemen Sumber Daya Manusia, Edisi Pertama Salemba Empat, Jakarta, 2012.

Moeheriono, Pengukuran Kinerja Berbasis Kompetensi. Raja Grafindo, Jakarta 
Mulyana, Deddy, Metodologi Penelitian Kualitatif, PT Remaja Rosdakarya Bandung, 2002

Nawawi, Hadari, Evaluasi dan manajemen kinerja di lingkungan perusahaan dan industri. Gajah Mada Univercity Press. Yogyakarta, 2006

Notoatmodjo, Soekidjo, Promosi kesehatan dan Perilaku Kesehatan. Rineka cipta, Jakarta, 2012.

Panggabean, Mutiara S, Manajemen Sumber Daya Manusia, Ghalia Indonesia, Jakarta, 2007

Mangkunegara A.Prabu, Manajemen sumber daya manusia, PT. Remaja Rosdakarya, Bandung, 2010.

Reindy Gustyawan, Pengaruh Komunikasi Interpersonal Terhadap Kinerja Karyawan di Divisi Sekretaris Perusahaan PT. Dirgantara Indonesia (Persero), Universitas Telkom, Bandung, 2015.

Reiner, Michael D. Reiner Jihong Zhao.”The Determinants of Job Satisfaction Among United States Air Force Security Police A Test of Rival Theoretical Predictive Models, SAGE Jurnal, Vol 19, Issue 3, 1999

Rivai, Veithzal dan Sagala, Ella Jauvani, Manajemen Sumber Daya Manusia untuk Perusahaan dari Teori ke Praktik. PT Raja Grafindo. Jakarta, 2013.
Robbins, Stephen P, Timothy A. Judge, Perilaku Organisasi, PT. Salemba Empat, Jakarta, 2008.

Sarwono.S.W. Psikologi Remaja. PT Raja Grafindo Persada,Jakarta, 2009

Sedarmayanti, Manajemen Sumber Daya Manusia, Reformasi Birokrasi Manajemen Pegawai Negeri Sipil. Rafika Aditama, Bandung, 2011

Setiyawan, Budi dan Waridin. Pengaruh Disiplin Kerja Karyawan Dan Budaya Organisasi Terhadap Kinerja Di Divisi Radiologi RSUP Dokter Kariadi Semarang. JRBI. Vol 2. No 2. 2006.

Siagian, Sondang P., Manajemen Sumber Daya Manusia. PT Bumi Aksara: Jakarta, 2008

Simamora, Henry. Manajemen Sumber Daya Manusia. STIE YKPN., Yogyakarta, 2008

Simanjuntak, Payaman, Ekonomi Sumber Daya Manusia. Lembaga Penerbit Fakultas Ekonomi Universitas Indonesia, Jakarta.2011

Soobaroyen, T. Management control systems and dysfungsional behavior and empirical investigation, management accounting section meeting conference reviewers. 2007.

Stringer, Janett. L. Basic Concepts in Pharmacology. New York: McGraw Hill.2007. 
Sumantri, Arif. Kesehatan Lingkungan \& Perspektif Islam, Kencana, Jakarta, 2007

Sutrisno Hadi. Metodologi Research untuk Penulisan Paper, Skripsi, Thesis dan Disertasi, Jilid Tiga. Andi, Yogyakarta, 2001
Wibowo, Manajemen Kinerja-Edisi Ketiga, PT. Raja Grafindo Persada. Jakarta, 2010.

Wirawan, Evaluasi Kinerja Sumber Daya Manusia Teori Aplikasi dan Penelitian. Salemba Empat, Jakarta, 2009 